\title{
LOCALIZAÇÃO DE CENTRO DE TRIAGEM DE PAPEL PARA ESCOLAS DO BAIRRO DA VILA MARIANA, SÃO PAULO
}

\author{
LOCATION OF PAPER SORTING CENTER FOR SCHOOLS IN VILA MARIANA \\ NEIGHBORHOOD, SÃO PAULO
}
Isabela Rubim Costa Soares ${ }^{1}$, Marina Gutierres Biagio ${ }^{2}$, Max Filipe Silva Gonçalves ${ }^{3}$, \& Marcos Wagner Jesus Servare Junior ${ }^{*}$
123 Universidade Presbiteriana Mackenzie. ${ }^{4}$ Universidade Federal do Espírito Santo. ${ }^{1}$ isarubimcs@ gmail.com ${ }^{2}$ mgbiagio@gmail.com ${ }^{3}$ max.goncalves@mackenzie.br 4* marcoswjunior@ gmail.com

\section{ARTIGO INFO.}

Recebido em: 28.10.2020

Aprovado em: 18.11.2020

Disponibilizado em: 03.12.2020

\section{Palavras-Chave:}

Centro de Triagem; Logística Reversa; Papel;

Resíduos Sólidos Urbanos.

\section{KEYWORDS:}

Sorting Center; Reverse logistic; Paper; Urban solid waste.

*Autor Correspondente: Servare Junior, M. W. J.

\section{RESUMO}

O perfil do cidadão tem se modificado em relação aos impactos causados pelo alto consumo e o descarte incorreto gerado pelos seus resíduos; com isso os cidadãos tem continuamente buscado soluções que minimizem os impactos de suas ações. Assim, o presente estudo teve por objetivo identificar a melhor localização para a instalação do elo Centro de Triagem da logística reversa de aparas de papel gerados em escolas do bairro Vila Mariana, levando em consideração as variáveis de decisão. Por meio da metodologia escolhida definiram-se os seguintes objetivos específicos: mapear as escolas no bairro da Vila Mariana, na cidade de São Paulo; identificar as variáveis de decisão que influenciam e devem ser levadas em consideração para determinar as estimativas; avaliar a instalação de um Centro de Triagem para atender a região utilizando modelo de localização, centro de gravidade. Considerando o método escolhido, as escolas da região foram mapeadas possibilitando definir a melhor localização para o Centro de Triagem, bem como avaliar a sua instalação pelos critérios de volume de aparas de papel gerado pelas escolas mapeadas, custo do transporte do resíduo das escolas até o Centro de Triagem e a distância entre as escolas e o Centro de Triagem.

\begin{abstract}
The citizen's profile has changed in relation to the impacts caused by high consumption and the incorrect disposal generated by its waste; As a result, citizens have continuously sought solutions that minimize the impacts of their actions. Thus, the present study aimed to identify the best location for the installation of the Sorting Center link for the reverse logistics of paper chips generated in schools in the Vila Mariana neighborhood, taking into account the decision variables. Through the chosen methodology, the following specific objectives were defined: mapping schools in the Vila Mariana neighborhood, in the city of São Paulo; identify the decision variables that influence and should be taken into account to determine the estimates; evaluate the installation of a Sorting Center to serve the region using a location model, center of gravity. Considering the method chosen, schools in the region were mapped, making it possible to define the best location for the Sorting Center, as well as to evaluate its installation according to the criteria of volume of paper chips generated by the mapped schools, cost of transporting the waste from schools to the Sorting Center and the distance between schools and the Sorting Center.
\end{abstract}



papel para escolas do bairro da Vila Mariana, São Paulo. Brazilian Journal of Production Engineering, 6(7), 110-119.

\section{INTRODUÇÃO}

Em um cenário com rápidas mudanças e inovações tecnológicas, o perfil dos cidadãos tem se modificado sobre os impactos causados pelo alto consumo, utilização desenfreada dos recursos naturais, a contaminação dos lençóis freáticos, o local de descarte dos resíduos, entre outros; levando a buscar soluções que minimizem os impactos de suas ações no meio ambiente e dos diversos assuntos envolvidos de forma sistêmica.

A expressão "reforma ecológica" citada por Viola (1987), indica a necessidade de melhorias nos ambientes urbanos, os mais expostos ao lixo urbano e as consequências ambientais causadas pela sua má gestão. Assim, a gestão de resíduos sólidos se torna parte fundamental da sustentabilidade urbana que segundo Jacobi e Besen (2011), é um dos maiores desafios com que a sociedade moderna se defronta devido à falta de gerenciamento adequado e disposição final. E, portanto, utilizar ferramentas e tecnologias modernas permitirão auxiliar a cadeia de suprimentos nesse contexto (Servare Junior, et al., 2018).

Desta forma, a gestão dos resíduos sólidos urbanos e a sustentabilidade urbana abordam os âmbitos sociais, ambientais e econômicos. Além de abranger a esfera legislativa através da Política Nacional de Resíduos Sólidos (PNRS) instituída pela Lei 12.305/2010, classificando a gestão de resíduos sólidos como "o conjunto de princípios, objetivos, instrumentos, diretrizes, metas e ações adotados pelo Governo Federal” (Brasil, 2010, Art. $4^{\circ}$ ).

Então faz-se necessário que os poderes públicos e privados façam a gestão adequada dos resíduos sólidos, sem esquecer a importância da conscientização de toda a sociedade quanto a esta questão. Buscar alternativas e estratégias para adoção de uma gestão sistêmica dos resíduos sólidos têm como foco o futuro do meio ambiente e do planeta, é o que mobilizam acadêmicos e profissionais. Municípios e governo vêm direcionando esforços dispersos neste sentido, o que exige transformações e a convergência para que tais impactos sejam minimizados. Atualmente, no contexto de redução de investimento, utilizar de forma eficiente a estrutura disponível ou redução de custos no projeto é um essencial para a competitividade das empresas (Servare Junior, et al., 2020).

Nos termos da PNRS, a responsabilidade compartilhada pelo ciclo de vida dos produtos é o compartilhada entre fabricantes, importadores, distribuidores e comerciantes, dos consumidores e dos titulares dos serviços públicos de limpeza urbana e de manejo dos resíduos sólidos, a fim de minimizar o volume de resíduos sólidos e rejeitos gerados, bem como para reduzir os impactos causados à saúde humana e à qualidade ambiental decorrentes do ciclo de vida dos produtos, nos termos desta Lei.

Nos últimos anos são observados diversos trabalhos no contexto da logística reversa na literatura, abordando um amplo espectro de produtos retornados, dentre eles, óleo de cozinha (Ferri, et al., 2017; Gonçalves, Leite, \& Shimada, 2018; Servare Junior, \& Cardoso, 2020), óleo lubrificante (Machado, Feres, \& Gonçalves, 2019), pneus (Fornazari, et al., 2019) e embalagens cartonadas (Trevisan, Xavier, \& Gonçalves, 2019).

Segunda a review de 2015 da CEMPRE (2017) - Compromisso Empresarial para Reciclagem, cerca de 31,9\% dos resíduos sólidos são compostos por resíduos secos recicláveis. Dentre estes, 
Citação (APA): Soares, I. R. C., Biagio, M. G., Gonçalves, M. F. S., \& Servare Junior, M. W. J. (2020). Localização de centro de triagem de papel para escolas do bairro da Vila Mariana, São Paulo. Brazilian Journal of Production Engineering, 6(7), 110-119.

o papel e o papelão representam $13,1 \%$, enquanto plástico $13,5 \%$, vidro $2,4 \%$ e metais $2,9 \%$. A reciclagem do papel ajuda na geração de emprego, economia de energia, água e outros recursos naturais, como as árvores.

Neste contexto, o presente artigo tem por objetivo utilizar um dos diversificados métodos de localização para definir o melhor local como centro de triagem para as escolas do bairro da Vila Mariana, em São Paulo a partir da técnica de Centro de Gravidade. Considerando o elevado índice de geração do resíduo sólido seco papel, apontar qual a melhor localização para um centro de triagem de papel para escolas no bairro da Vila Mariana.

Neste trabalho a Seção 1 permitirá a compreensão do tema do trabalho através de sua introdução. A Seção 2 apresenta uma revisão literária com informações e contextualizações sobre resíduos sólidos, resíduos sólidos urbanos, a caracterização do resíduo estudados, os elos e conceitos da logística reversa, centro de triagem, o gerenciamento de coleta e aborda também gestões de sustentabilidade, reciclagem e localização.

A implementação do método de Centro de Gravidade na Seção 3, incluindo o mapeamento das instituições de ensino e os dados coletados e, por fim a Seção 4 apresenta as considerações finais, as quais foram determinadas e desenvolvidas durante toda a realização do trabalho.

\section{REVISÃO DE LITERATURA}

\subsection{LOGÍSTICA DO RESÍDUO SÓLIDO URBANO}

Roger e Tibben-Lembke (2001) ampliaram o conceito de Logística Reversa (LR), englobando o planejamento, estruturação, custo efetivo do fluxo de matéria-prima e a implementação e controle de eficiência, além do estoque de processo, levando em consideração desde o ponto de consumo até o ponto de origem, com a finalidade de recapturar valor ou adequar o seu destino.

Dornier, et al., (2000) redefiniram a abrangência da LR incluindo todas as formas de movimentação dos produtos e informações como logística, dizendo que a mesma é a gestão de fluxos entre funções de negócio.

A ideia de "Apoio ao Ciclo de Vida" surgiu quando Bowersox e Closs (2001) prolongaram a logística além do fluxo direto das matérias primas e a relevância dos fluxos reversos de produtos em geral.

Por sua vez, a sustentabilidade é definida por Silva (2003) como uma utilização equilibrada dos recursos naturais, na medida para satisfazer o bem-estar e as necessidades da atual geração, bem como a manutenção para gerações futuras.

Durante a Cúpula Mundial sobre o Desenvolvimento Sustentável, da ONU, realizada em Joanesburgo, África do Sul, em 2010 foram definidos os três pilares da sustentabilidade: o econômico, o ambiental e o social. O âmbito econômico visa empreendimento viáveis, enquanto o ambiental busca a interação dos processos sem causar danos permanentes ao meio ambiente e o social visa a inclusão social e as boas condições de trabalho (Oliveira, et al., 2012).

Sendo a reciclagem uma importante ferramenta da sustentabilidade, reciclagem é definida como um processo de reaproveitamento dos resíduos sólidos, em que os seus componentes são 
Citação (APA): Soares, I. R. C., Biagio, M. G., Gonçalves, M. F. S., \& Servare Junior, M. W. J. (2020). Localização de centro de triagem de papel para escolas do bairro da Vila Mariana, São Paulo. Brazilian Journal of Production Engineering, 6(7), 110-119.

separados, transformados e recuperados, envolvendo economia de matérias-primas e energia, combate ao desperdício, redução da poluição ambiental e valorização dos resíduos, com mudança de concepção em relação aos mesmos (Galbiati, 2012).

\subsection{LOCALIZAÇÃO}

No âmbito empresarial a escolha de uma localização é agir em equilíbrio com três objetivos principais (Slack, et al., 2015):

- Os custos variáveis, influenciados pela determinação do local, como custo de mão de obra, custo da Terra, custo de energia, custo de transportes, fatores da comunidade, entre outros;

- O serviço que a operação presta, dependendo da operação a divulgação da mesma pode ser influenciada pelo lugar onde a mesma ocorre, como por exemplo o objetivo deste trabalho que visa a acessibilidade aos consumidores de aparas de papel;

- E o último objetivo defendido é o potencial de faturamento da operação, o mesmo admite que a receita da operação pode não ser significativamente influenciada pela localização. No entanto, é influenciado diretamente pela demanda, custos de oferta e de operação fatores diretamente relacionados ao seu posicionamento.

Para calcular a localização de um ou mais pontos, levando em consideração os objetivos apontados, existem diversos estudos matemáticos, teorias que levam em consideração fatores como, distância a pontos de demanda, distância a pontos de oferta, volume de transporte,

custo de transporte, entre outros. No entanto, durante a pesquisa exploratória, verificou-se que diversos estudos têm levado como base o método de centro de gravidade o qual será utilizado também neste artigo.

Há diversos trabalhos embasados no método de centro de gravidade que afirmam ser o método mais utilizado para determinação de uma planta única. Segundo Slack et al. (2015), o método do centro de gravidade (CG) é utilizado para definir a uma localização onde evidencia a minimização de custo de transporte. Já que o método se baseia na ideia de que toda localização tem um custo. Já Martins e Laugeni (2015), explicam que o CG, além de procurar avaliar o local levando em consideração o menor custo, ele pondera o fornecimento de matérias-primas e os mercados consumidores.

Os autores, ainda, apresentam as Expressões (1) e (2), para definição das coordenadas no cálculo do CG, são apresentadas a seguir.

Onde:

$$
\begin{aligned}
& x=\frac{\sum V_{i} C_{i} x_{i}}{\sum V_{i} x_{i}} \\
& y=\frac{\sum V_{i} C_{i} y_{i}}{\sum V_{i} y_{i}}
\end{aligned}
$$

$V_{i}=$ Volume em $\mathrm{kg}$ transportada para o local $\mathrm{i}$;

$C_{i}=$ Custo $(\mathrm{R} \$)$ por unidade de volume $(\mathrm{kg})$ transportado para o local $\mathrm{i}$;

$x_{i}=$ Coordenada na direção $\mathrm{x}$ do local $\mathrm{i}$;

$y_{i}=$ Coordenada na direção y do local i. 

papel para escolas do bairro da Vila Mariana, São Paulo. Brazilian Journal of Production Engineering, 6(7), 110-119.

\section{Centro de gravidade}

O estudo tem como base a relevância da logística reversa para auxiliar na redução do descarte do material. O resíduo papel, além de ser o segundo mais utilizados na atualidade, como já mencionado na introdução (CEMPRE 2017), apresenta a maior aceitação pelas indústrias produtoras que já o utilizam para a produção de papéis de embalagens, papéis tissue, cartões, entre outros (Macedo; Valença, 1995), facilitando sua comercialização.

Para que o impacto seja maior, a localização precisa levar em consideração o volume de resíduo a ser coletado na região (Martins, \& Laugeni, 2015). Sendo assim, foi levado em consideração um estabelecimento que apesar de não ser classificado como grande gerador por Jacobi e Besen (2011) torna-se um dos principais geradores ao considerar o agrupado das instituições de ensino, localizados na área de estudo.

Verificando o registro das instituições na Secretaria da Educação do estado de São Paulo (São Paulo, 2018) o bairro da Vila Mariana aparece em terceiro lugar com a maior quantidade de escolas particulares. O método de localização escolhido, centro de gravidade (CG), fornece a melhor localidade para o centro de triagem levando em consideração o custo variável, a distância e o volume, além de ser o método mais utilizados em estudos na atualidade. (Sato, 2002)

Dentre os diversos modelos de aplicação para a determinação do ponto ideal para a localização do centro de triagem do material, foi aplicado o método do Centro de Gravidade.

O método tende a minimizar o custo de transporte. Para isso, leva em consideração apenas os fatores quantitativos de volume, custo e distância, suprimindo os fatores qualitativos, como: viabilidade da localização, qualidade do terreno, mão de obra, entre outros.

Na Figura 1, está descrito de maneira simplificada o fluxo da rede de logística reversa em que o centro de triagem proposto no estudo estará inserido. O primeiro elo é composto pelos geradores de resíduos, que neste estudo é representado pelas instituições de ensino e seus alunos. Segundo Jacobi e Besen (2011) os resíduos gerados nas escolas são classificados como resíduo domiciliar, porém o atual estudo trabalha com um grupo de escolas que juntos geram um grande volume de resíduos tornado o grupo de escolas estudado em um grande gerador de resíduos.

O segundo elo do fluxo representa o centro de triagem. Nesta etapa, o volume de papel recebidos das escolas é segregado conforme seu tipo. Após, o material é separado para ser encaminhado para as empresas de reciclagem e para as indústrias que reutilizam esse tipo de material, como por exemplo a indústria de papel e celulose.

Sendo assim, o terceiro elo é para onde os resíduos são direcionados e recebidos por empresas recicladoras para serem recicladas ou fábricas de papel para retornarem ao fluxo logístico direto de fabricação sendo utilizado como parte da matéria-prima. 
Citação (APA): Soares, I. R. C., Biagio, M. G., Gonçalves, M. F. S., \& Servare Junior, M. W. J. (2020). Localização de centro de triagem de papel para escolas do bairro da Vila Mariana, São Paulo. Brazilian Journal of Production Engineering, 6(7), 110-119.

Figura 1. Proposta de rede logística reversa para o centro de triagem da Vila Mariana.

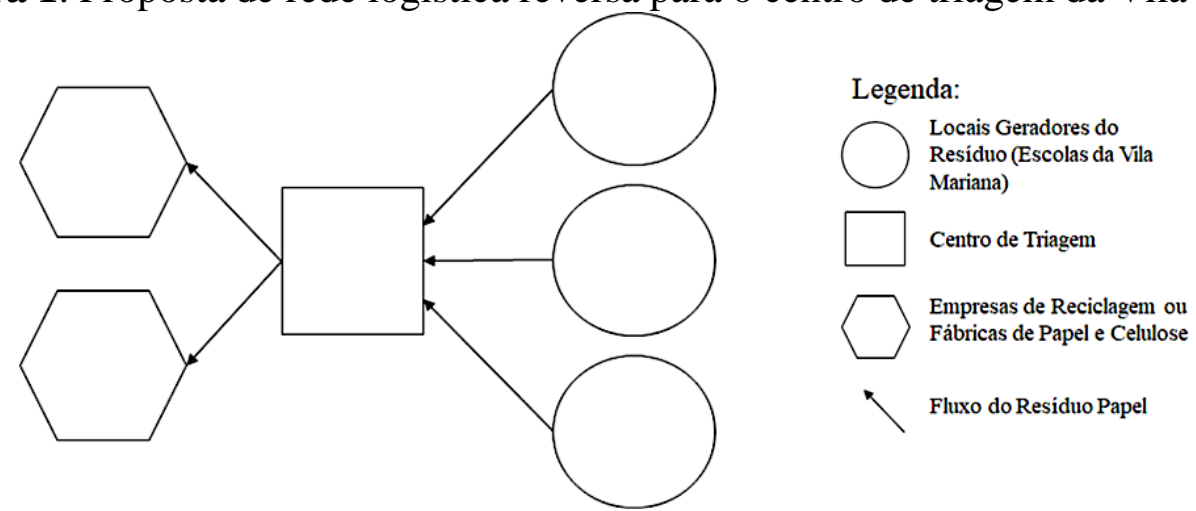

Fonte: Adaptado de Ferri, et al., (2014).

\subsection{COLETA DE DADOS}

Para o desenvolvimento do estudo, as escolas foram selecionadas de acordo com a sua localidade no cadastro na secretaria da educação, sendo que todas aquelas que havia registro no bairro da Vila Mariana foram levados em consideração, veja Tabela 1.

Tabela 1. Quantidade de escolas identificadas no bairro da Vila Mariana

\begin{tabular}{cc}
\hline Escolas & Quantidade \\
\hline Privadas & 49 \\
Municipais & 3 \\
Estaduais & 6 \\
\hline Total & $\mathbf{5 8}$ \\
\hline
\end{tabular}

Fonte: Adaptado da Secretaria da Educação do estado de São Paulo

Para a localização e distribuição das pesquisas suas localidades foram fornecidas pela Secretaria da Educação do estado de São Paulo, através do levantamento realizado pelo Censo Escolar de 2017 (INEP, 2018), o qual apresenta rua, número, bairro, município, informações convertidas em longitude e latitude através da plataforma de mapas do Google LLC, veja Figura 2.

Figura 2. Mapa de localização das escolas da Vila Mariana
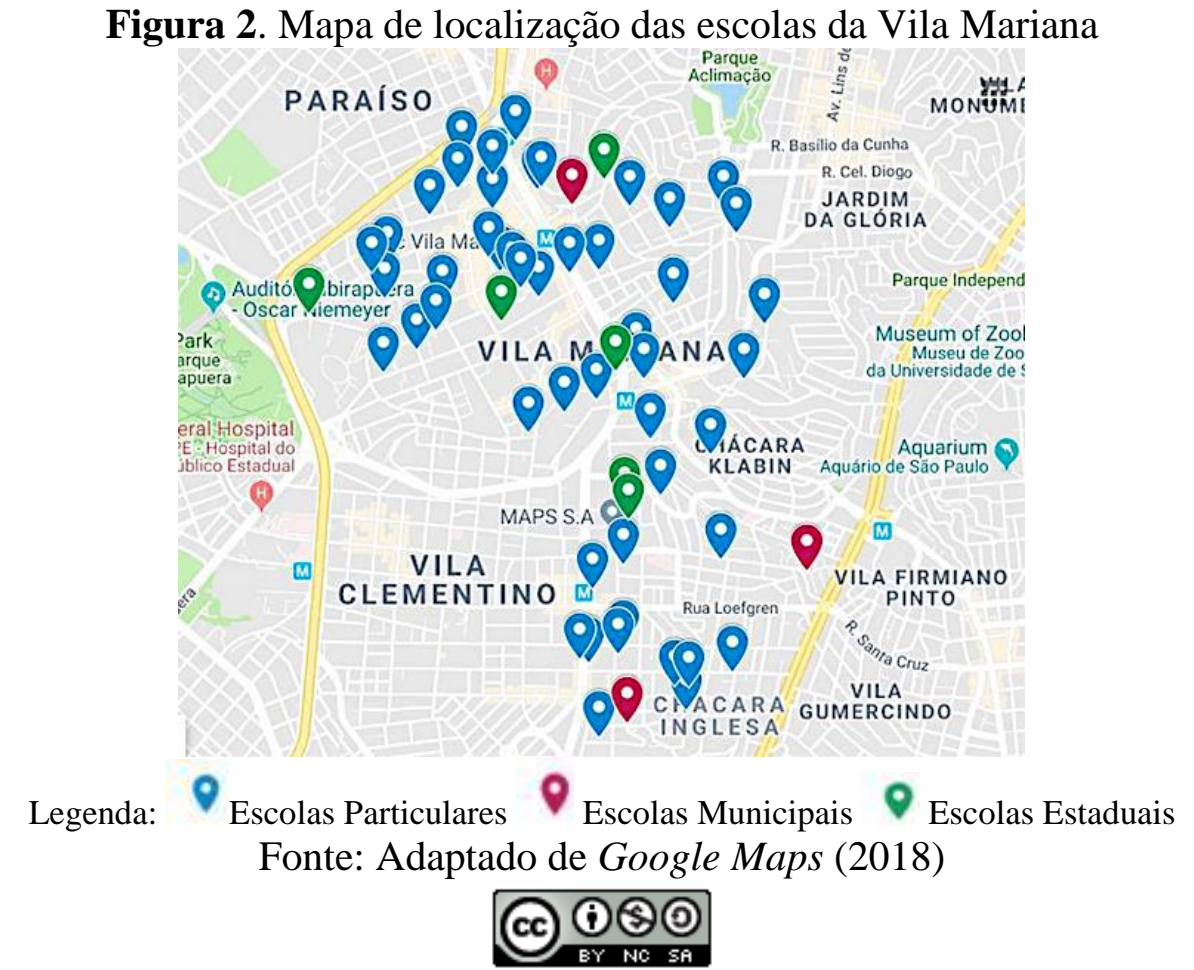
Citação (APA): Soares, I. R. C., Biagio, M. G., Gonçalves, M. F. S., \& Servare Junior, M. W. J. (2020). Localização de centro de triagem de papel para escolas do bairro da Vila Mariana, São Paulo. Brazilian Journal of Production Engineering, 6(7), 110-119.

O Censo Escolar de 2017 (INEP, 2018) trouxe também o levantado do número de alunos por instituição de ensino, independentemente do tamanho da mesma, desde creches até instituição de ensino de nível técnico, sendo assim este trabalho não levará em consideração o nível de escolarização das instituições de ensino.

Com a ausência da localização de uma informação mais precisa na pesquisa exploratória na literatura acadêmica e informações disponíveis em sites do governo sobre o consumo de papéis nos diversos níveis de escolaridade, foi levada em consideração a premissa de que o volume de resíduos gerados é proporcional ao número de alunos das instituições.

\section{RESULTADOS}

Para a realização do trabalho a localização foi utilizada em longitude (X) e latitude (Y) facilitando a aplicação das fórmulas do método. De acordo com Ferri et al. (2014) o custo do transporte deveria ser de $\mathrm{R} \$ 10,50$ por quilômetro por tonelada, ou seja, aproximadamente $\mathrm{R} \$$ 0.01 por quilômetro por quilograma, levando em relação a correção da inflação medida pelo IBGE de 2016, 6.29\% (2016 apud Portal Brasil, 2018), de 2017 2.95\% (2017, apud Governo do Brasil, 2018) e a previsão da inflação de 2018 de 4.23\% (2018, apud Governo do Brasil, 2018) teríamos um custo de $\mathrm{R} \$ 11,98$ por quilômetro por tonelada, no qual o custo por quilômetro por quilograma seria de aproximadamente $\mathrm{R} \$ 0.01$, portanto apesar da correção, não houve impacto significativo no custo de transporte.

A Revista Exame em 2016 publicou uma matéria onde revela resultados de um estudo realizado pela ABRELPE, onde a mesma afirma no estado de São Paulo um habitante tende a produzir 1,393 kg por dia de resíduos sólidos urbanos. Como mencionado anteriormente apenas 31,9\% os resíduos sólidos são compostos por resíduos secos recicláveis, destes, 13,1\% representam papel e papelão (ABRELPE 2016).

No último censo de 2010 o IBGE verificou que a cidade de São Paulo tinha 11.253.503 habitantes, sendo o total de alunos nas escolas registradas no bairro da Vila Mariana na cidade de São Paulo é de 23.043 alunos (INEP, 2018), conforme dados tabulados na Tabela 2.

Tabela 2. Dados utilizados

\begin{tabular}{cc}
\hline Distância & longitude $(\mathbf{X})$ e latitude $(\mathbf{Y})$ \\
\hline Custo de Transporte & $\mathrm{R} \$ 0,01$ por quilômetro por quilograma \\
Volume total & $1786,60 \mathrm{Kg} /$ mês \\
Número de alunos & 23043 alunos \\
\hline
\end{tabular}

Portanto, neste artigo as fórmulas (1) e (2) foram adaptadas nas expressões (3) e (4), considerando as coordenadas geográficas do ponto ótimo.

$$
\begin{gathered}
x=\frac{\sum \text { latitude } * n^{\mathrm{o}} \text { de alunos }}{\sum n^{\underline{0}} \text { de alunos }} \\
y=\frac{\sum \text { longitude } * n^{\mathrm{o}} \text { de alunos }}{\sum n^{\mathrm{o}} \text { de alunos }}
\end{gathered}
$$

Obtendo assim, o ponto $\mathrm{X}=-23.58769126$ e $\mathrm{Y}=-46.63775054$ como ponto ótimo, conforme localizações plotadas na Figura 3. 

papel para escolas do bairro da Vila Mariana, São Paulo. Brazilian Journal of Production Engineering, 6(7), 110-119.

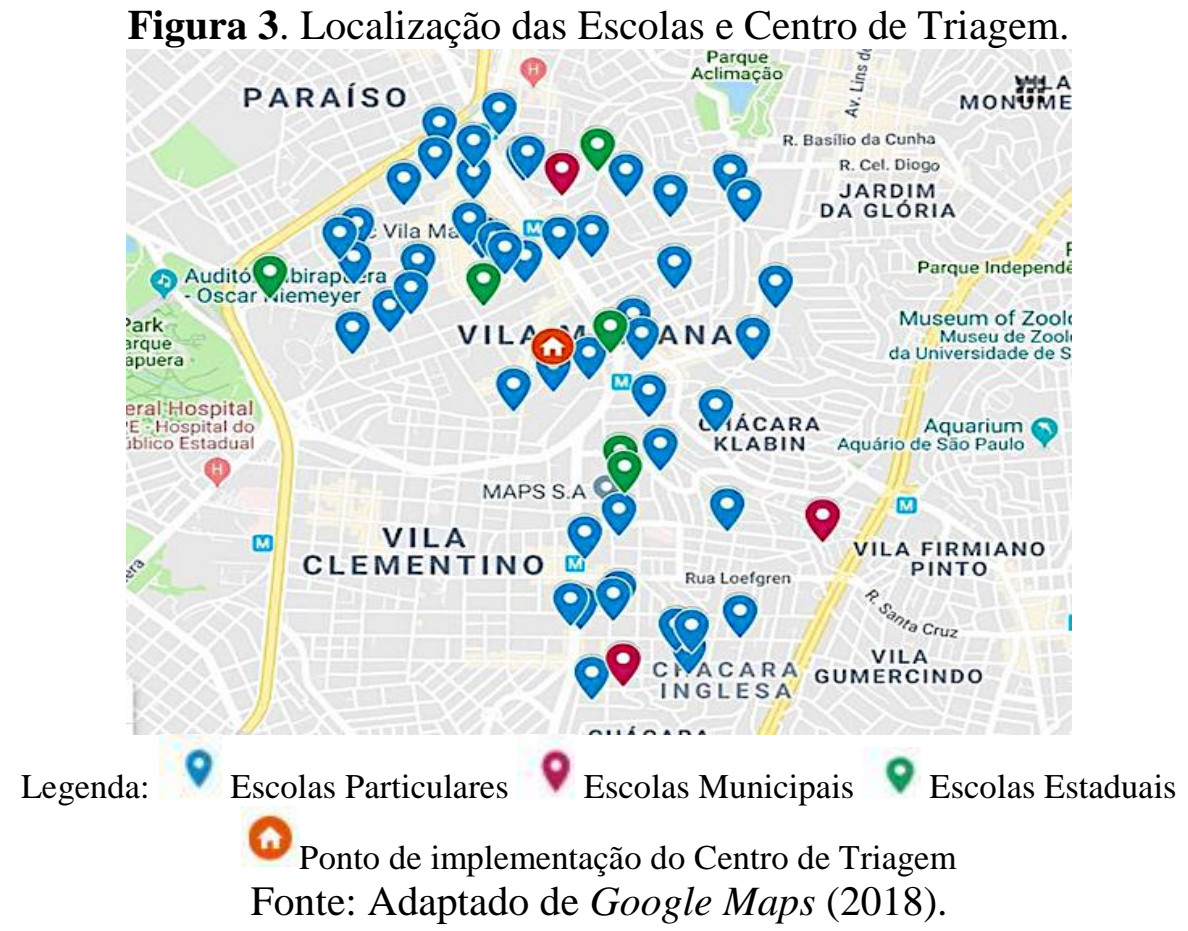

Para efeito de avaliação do ponto definido, o método CG foi aplicado considerando a escola com o maior número de alunos e, consequentemente, maior gerador de resíduos de aparas de papel, o ponto ideal para a instalação do centro de triagem. A Instituição localizada na coordenada $\mathrm{X}=-23.59882$ e $\mathrm{Y}=-46.63622$. Por meio dos cálculos, foi observado um custo mensal de transporte $\mathrm{R} \$ 1736,19$ superior ao ponto ótimo (Tabela 3).

Tabela 3. Comparação entre ponto ótimo e ponto maior gerador de resíduo

\begin{tabular}{lcc}
\hline & Ponto Ótimo & Ponto de Maior Volume \\
\hline Custo de transporte & $\mathrm{R} \$ 4.835,69$ & $\mathrm{R} \$ 6.571,88$ \\
\hline
\end{tabular}

\section{CONSIDERAÇÕES FINAIS}

Com o aumento da população e consequentemente do aumento do consumo dos diversos recursos naturais, o ser humano passou a fazer esforços para compreender e aplicar o consumo consciente e melhorias de como tratar os resíduos gerados, bem como o seu descarte. Temas de cunho ambiental foram ganhando maior proporção à medida que o ser humano compreendia o impacto do consumo desenfreado e do descarte irregular.

O presente estudo buscou encontrar a melhor localização de centro de triagem para o resíduo papel, o segundo maior tipo de resíduo seco gerado pelo descarte da população, originado nas escolas no bairro da Vila Mariana na cidade de São Paulo.

Para isso, foi necessária uma pesquisa para encontrar os endereços das escolas da Vila Mariana e mapeá-las. Além disso, foram identificas as variáveis de decisão que influenciaram no desenvolvimento do método (CG) e que foram importantes para determinar as estimativas, são elas: a quantidade de alunos por escola, a quantidade de resíduo gerado e as distâncias envolvidas. Ainda, utilizando as informações obtidas foi possível avaliar a localização da instalação do Centro de Triagem por meio do método centro de gravidade.

Levando em consideração as informações atribuídas durante o estudo, é possível estimar a quantidade de papel gerado nas escolas e, consequentemente, a capacidade do centro de 
Citação (APA): Soares, I. R. C., Biagio, M. G., Gonçalves, M. F. S., \& Servare Junior, M. W. J. (2020). Localização de centro de triagem de papel para escolas do bairro da Vila Mariana, São Paulo. Brazilian Journal of Production Engineering, 6(7), 110-119.

triagem; a distância do centro de triagem de cada escola, o custo de coleta por quilograma por quilômetro $(\mathrm{R} \$ 0,01)$ e o preço pago por quilo de papel $(\mathrm{R} \$ 0,18)$. Sendo assim, é possível definir que a capacidade mensal do centro de triagem está torno de $40.000 \mathrm{~kg}$ gerando o custo mensal de coleta de $\mathrm{R} \$ 402,97$ e lucro mensal com a venda mensal de papel por aproximadamente $\mathrm{R} \$ 7.039,10$.

Como limitações do presente estudo destaca-se a utilização de estimativas de dados. Além disso, não foram considerados os demais custos vinculados ao centro de triagem no cálculo de sua receita; a quantidade de papel gerada leva em consideração a quantidade de alunos, excluindo os demais funcionários; o método de centro de gravidade considera apenas os custos variáveis na sua aplicação, excluindo os custos fixos e os aspectos qualitativos da localização.

Para o desenvolvimento de estudos futuros, propõe-se a ampliação da amostra e região abrangida, considerar outros tipos de resíduos gerados nos estabelecimentos de ensino, considerar outras organizações que apoiem a iniciativa visando aumentar o volume coletado e, consequentemente, a quantidade de material para reciclar e reutilizar.

\section{REFERÊNCIAS}

ABRELPE (2016). Resíduos Sólidos Urbanos: Panorama dos resíduos sólidos no Brasil. Disponível: http://www.abrelpe.org.br/Panorama/panorama2016.pdf. Acesso: 24 abr. 2018.

Bowersox, D. J., \& Closs, D. J. (2001). Logística empresarial: o processo de integração da cadeia de suprimento. São Paulo: Atlas.

Brasil (2010). Lei $n^{\circ} 12.305$, de 2 de agosto de 2010, que institui a Política Nacional de Resíduos Sólidos. Disponível: http://www.planalto.gov.br/ccivil_03/_ato20072010/2010/lei/112305.htm\#: :text=LEI\%20N\%C2\%BA\%2012.305\%2C\%20DE\%202\%20DE $\% 20$ AGOSTO $\% 20 D E \% 202010 . \&$ text=Institui $\% 20 \mathrm{a} \% 20 \mathrm{Pol} \% \mathrm{C} 3 \%$ ADtica $\% 20$ Nacional $\% 20 \mathrm{~d}$ $\mathrm{e}, 1998 \% 3 \mathrm{~B} \% 20 \mathrm{e} \% 20 \mathrm{~d} \% \mathrm{C} 3 \% \mathrm{~A} 1 \% 20$ outras$\% 20$ provid $\% \mathrm{C} 3 \%$ AAncias.\&text $=$ Art.\&text $=\% \mathrm{C}$ $2 \% \mathrm{~A} 7 \% 202 \mathrm{o} \% 20 \mathrm{Esta} \% 20 \mathrm{Lei}, \mathrm{s} \% \mathrm{C} 3 \% \mathrm{~A} 3 \mathrm{o} \% 20$ regulados\%20por\%20legisla\%C3\%A7\%C3\% A3o\%20espec\%C3\%ADfica Acesso em: 28 out. 2020.

Brasil (2018). Mercado financeiro prevê inflação em 4,23\% em 2018, 2018. Disponível: http://www.brasil.gov.br/noticias/economia-e- financas/2018/11/mercado-financeiro-preveinflacao-em-4-23-em-2018 Acesso: 20 nov. 2018.

Brasil (2017). Inflação termina 2016 no menor nível em três anos. Disponível: http://www.brasil.gov.br/economia-e-emprego/2017/01/inflacao-termina-2016-no-menornivel-em-tres-anos-1 Acesso: 20 nov. 2018.

CEMPRE (2017). Pesquisa Ciclosoft 2016, Disponível: http://cempre.org.br/ciclosoft/id/8 Acesso: 21 out. 2020.

INEP (2018). Censo Escolar, 2018. Disponível: http://portal.inep.gov.br/web/guest/resultadose-resumos Acesso: 10 Ago. 2018

Dornier, P. P. et al., (2000) Logística e Operações Globais. São Paulo: Atlas.

Ferri, G. L., Chaves, G. L. D., \& Ribeiro, G. M (2014). Análise e localização de centros de armazenamento e triagem de resíduos sólidos urbanos para a rede de logística reversa: um estudo de caso no município de São Mateus, ES. Production, 25(1), 27-42. DOI: 10.1590/s0103-65132014005000014.

Ferri, G. L. et al., (2017). Models for localizing facilities in solid waste management: a bibliometric review. Brazilian Journal of Production Engineering, 3, p. 40-56.

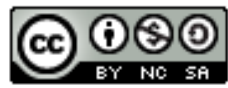


Citação (APA): Soares, I. R. C., Biagio, M. G., Gonçalves, M. F. S., \& Servare Junior, M. W. J. (2020). Localização de centro de triagem de papel para escolas do bairro da Vila Mariana, São Paulo. Brazilian Journal of Production Engineering, 6(7), 110-119.

Fornazari, A. C., et al., (2019) Evaluation of the structure of the tire network reverse logistics: a case study. Iberoamerican journal of project management, 10, p. 1, 2019.

Gonçalves, M. F. S., Leite, A. C., \& Shimada, R. D. (2018) Avaliação da estrutura da logística reversa do óleo residual de cozinha (ORC) em São Paulo. Revista Gestão Industrial, 14, p. 1.

Galbiati A. F. (2012) O Gerenciamento Integrado de Resíduos Sólidos e a Reciclagem. Disponível em: <http://web-resol.org/textos/97.pdf>. Acesso em: 6 Out 2020

Jacobi P. R., \& Besen G.R. (2011) Gestão de resíduos sólidos em São Paulo: desafios da sustentabilidade. Estudos Avançados, 25(71). DOI: 10.1590/S0103-40142011000100010

Macedo, A. R. P., \& Valença, A. C. V. (1995) BNDES Setorial. Reciclagem de papel. Rio de Janeiro, 2, p. [4]-22.

Machado, G. C., Feres, P. P., \& Gonçalves, M. F. S. (2019) Reverse logistics: feasibility analysis of the collection and restitution of lubricating oil used or contaminated. Journal of Engineering and Technology for Industrial Applications, 5, p. 1. DOI: 10.5935/24470228.20190009

Maps. (2018) Google maps. Disponível: https://www.google.com.br/maps Acesso: 15 jul. 2018.

Martins, P. G., \& Laugeni, F. P. (2015) Administração da Produção. 3. ed. São Paulo: Saraiva. Oliveira L. R., et al., (2012) Sustentabilidade: da evolução dos conceitos à implementação como estratégia nas organizações. Production, Niterói, 22(1), 70-82. DOI: 10.1590/S010365132011005000062

Rogers, D. S., \& Tibben-Lembke, R. S. (2001) An examination on reverse logistics practices. Journal of Business Logistics. 22(2),129-148. 10.1002/j.2158-1592.2001.tb00007.x

São Paulo (2018) Cadastro de Escolas. 2018. Disponível: http://www.educacao.sp.gov.br/central-de-atendimento/downloads.asp. Acesso: 15 jul. 2018.

Sato, F. R. L. (2002) Problemas e métodos decisórios de localização de empresas. RAE Eletrônica, São Paulo, 1(2), 6-8.

Servare Junior, M. W. J., et al., (2018) Mathematical model for supply chain design with time postponement. Transportes, Rio de Janeiro, 6(4), 1-15. DOI: 10.14295/transportes.v26i4.1324 Servare Junior, M. W. J., \& Cardoso, P. A. (2020) Modelo matemático para postergação de tempo no projeto de rede logística reversa com níveis de capacidade. Brazilian Journal of Production Engineering, 6(7), 01-22. DOI: 10.47456/bjpe.v6i7.32475

Servare Junior, M. W. J., et al., (2020) A Linear Relaxation-Based Heuristic for Iron Ore Stockyard Energy Planning. Energies, Basel, 13(19). DOI: 10.3390/en13195232

Silva, J. A. da. (2003). Direito ambiental constitucional. 4a. Ed. São Paulo: Malheiros.

Trevisan, C. E., Xavier, W. S., \& Gonçalves, M. F. S. (2019) Roteirização de caminho ótimo para coleta seletiva de embalagens cartonadas na região central da cidade de Embu das Artes SP. Revista Brasileira De Gestão Ambiental, 13, p. 13-23.

Slack, N. et al. (2015) Administração da produção, 4ª . Ed, São Paulo: Atlas.

Viola, E. J. (1987). O movimento Ecológico no Brasil (1974-1986): do ambientalismo à ecopolítica.

Disponível:

http://www.anpocs.org.br/portal/publicacoes/rbcs_00_03/rbcs03_01.htm Acesso: 27 agosto 2018. 